\title{
Mechanisms of first-line antimicrobial resistance in multi-drug and extensively drug resistant strains of Mycobacterium tuberculosis in KwaZulu-Natal, South Africa
}

Navisha Dookie, A. Willem Sturm and Prashini Moodley*

\begin{abstract}
Background: In South Africa, drug resistant tuberculosis is a major public health crisis in the face of the colossal HIV pandemic.

Methods: In an attempt to understand the distribution of drug resistance in our setting, we analysed the rpoB, $k a t G$, inhA, pncA and embB genes associated with resistance to key drugs used in the treatment of tuberculosis in clinical isolates of Mycobacterium tuberculosis in the KwaZulu-Natal province.

Results: Classical mutations were detected in the $\mathrm{katG}$, inhA and embB genes associated with resistance to isoniazid and ethambutol. Diverse mutations were recorded in the multidrug resistant (MDR) and extensively drug resistant (XDR) isolates for the rpoB and pncA gene associated with resistance to rifampicin and pyrazinamide.

Conclusions: M.tuberculosis strains circulating in our setting display a combination of previously observed mutations, each mediating resistance to a different drug. The MDR and XDR TB isolates analysed in this study displayed classical mutations linked to INH and EMB resistance, whilst diverse mutations were linked to RIF and PZA resistance. The similarity of the XDR strains confirms reports of the clonality of the XDR epidemic. The successful dissemination of the drug resistant strains in the province underscores the need for rapid diagnostics to effectively diagnose drug resistance and guide treatment.
\end{abstract}

Keywords: Drug-resistance, First-line drugs, Multi-drug resistant-TB, Extensively drug-resistant-TB, Clonality

\section{Background}

Tuberculosis (TB) remains one of the greatest public health concerns of our time, exacerbated by drugresistant strains of Mycobcterium tuberculosis and coinfection with human immunodeficiency virus (HIV). In its latest global TB report in 2015, the world health organization (WHO) estimated that $3.5 \%$ of new cases and $20.5 \%$ previously treated patients have multi-drug resistant (MDR) TB; i.e. resistance to isoniazid (INH) and rifampicin (RIF). Of these cases, $9 \%$ have extensively drug resistant (XDR) TB. XDR TB strains display resistance to INH, RIF and additional resistance to a

\footnotetext{
* Correspondence: moodleyp@ukzn.ac.za

Medical Microbiology and Infection Prevention and Control, School of Laboratory Medicine and Medical Science, College of Health Science,

University of KwaZulu-Natal, Durban, South Africa
}

fluoroquinolone antibiotic and one of the three injectable second line agents: amikacin (AMIK), kanamycin (KAN) and capreomycin (CAP) [1].

Despite the implementation of therapeutic regimes combining INH, RIF, ethambutol (EMB) and pyrazinamide (PZA) [2], the escalation of MDR strains has compromised the utility of this drug combination. The morbidity and mortality rates associated with drug resistant $\mathrm{TB}$ is several times higher than with drug susceptible forms [1]. Treatment of drug resistant TB is further complicated by the decreased efficacy and higher toxicity associated with the second line drugs as well as the inability to provide early diagnostic data to guide treatment [3]. Conventional drug susceptibility testing relies on mycobacterial 
culture methods, providing results after weeks or months. Despite remarkable strides made in advancing diagnosis of drug-resistant $\mathrm{TB}$ with molecularbased diagnostics, such as the GeneXpert MTB/RIF assay, this technology currently only detects reistance to RIF [4].

The most common genes associated with resistance to the first-line drugs in M.tuberculosis have been identified based on the mode of action of each of the drugs and their demonstrated association with drug resistance. These include $\operatorname{rop} B$ (RIF), katG and $i n h A$ (INH), $p n c A$ (PZA) and $e m b B$ (EMB). The clinical relevance of these mutations have been amply discussed $[5,6]$. The recent application of whole genome sequencing has provided in-dept insight on the development and evolution of drug resistance, including the complexity of resistance in M.tuberculosis. Interestingly, over a hundered genetic loci implicated in drug resistance. A recent study identified mutations in fourty genes linked to INH resistance, highlighting the dynamic evolution of resistance-conferring mutations under drug pressure. Furthermore, muations associated with drug resistance play varying roles, which include causative or compensatory mutations or may result in increased fitness $[3,7]$. Cohen et al. demonstrated that M.tuberculosis isolates bearing the most prevalent RIF resistance mutation (rpoB S450L), were most likely to have to compensatory mechanisms to overcome fitness costs associated with the mutation [8]. In addition to this complexity, resistance-conferring mutations in M.tuberculoisis vary geographically and according to the strain type [3].

In the study described in this report, we analysed mutations in the ropB, katG, inhA, pncA and $e m b B$ genes and their association to resistance to the key first-line antimicrobials in clinical isolates from the KwaZulu-Natal province of South Africa.

\section{Methods}

\section{M. tuberculosis clinical isolates}

M. tuberculosis clinical isolates were selected from the storage collection of the Infection Control laboratory, University of KwaZulu-Natal. The isolates were from sputum specimens obtained from patients presenting to the Church of Scotland Hospital in the Tugella Ferry region of KZN, South Africa from 2005 to 2009. At initial isolation, the drug susceptibility profiles of the isolates were established in our laboratory using the $1 \%$ proportion method [9]. Sixty isolates were selected for the study: 10 drug susceptible (DS), 15 multi-drug resistant (MDR-TB) and 28 extensively drug resistant (XDR-TB). The H37Rv laboratory strain was included as a control.

\section{Determination of the Minimum Inhibitory Concentration (MIC)}

MIC was established using a multipoint inoculation technique on Middlebrook 7H10 agar medium supplemented with oleic acid-albumin-dextrose-catalase (OADC). Test plates contained INH, RIF and EMB at concentrations of $0.125 ; 0.25 ; 0.5 ; 1 ; 2 ; 4 ; 8 ; 16 ; 32 ; 64$ and $128 \mathrm{mg} / \mathrm{L}$. The plates were seeded with an M.tuberculosis suspension matched to spectrophotometer absorbance reading of 1 at a wavelenght of $600 \mathrm{~nm}$. Test plates were incubated at $37{ }^{\circ} \mathrm{C}$ for 21 days in the presence of $5 \% \mathrm{CO}_{2}$. The MIC of an isolate was recorded as the lowest antibiotic concentration that inhibited growth of the organism. Resistance to INH, RIF and EMB was defined as concentrations of $0.2,1.0$ and $5.0 \mathrm{mg} / \mathrm{L}$ respectively, in accordance to WHO guidelines [10]. Isolates were tested in triplicate to ensure test accuracy and reproducibility. Due to the technical difficulty associated with conducting PZA testing in an acid based medium, MIC's for the drug was not conducted.

\section{Genomic DNA extraction \& amplification}

Genomic DNA was extracted from cultures grown on Middlebrook 7H11 media using the CTAB-NaCl (Cetyl-trimethyl-ammonium Bromide-Sodium Chloride) method, as described previously [11]. The integrity and concentration of the DNA was determined using a NanoDrop 2000c spectrophotometer (Thermo Scientific). PCR amplification assays were carried out for the inh $A$, katG, rpoB, pncA and $e m b B$ genes. Primers for each of the genes were selected from published literature or designed using Primer3 design software [12]. The Expand Hi Fidelity PCR kit (Roche) was used in accordance to the guidelines set out by the manufacturer. Table 1 contains specific annealing temperatures and primer sequences used for amplification.

\section{DNA sequencing \& analysis}

Prior to sequencing, the quality of PCR amplicons were determined on a $1 \%$ agarose gel. Amplicons were purified using the Invitrogen PureLink PCR purification kit (Applied Biosystems) and sequenced using ABI Prism Big Dye Terminator cycle sequencing kit V3.1 (Applied Biosystems) together with the forward primers selected for PCR amplification. Nucleotide sequences were aligned to the $\mathrm{H} 37 \mathrm{Rv}$ reference strain using Genious V5.5.7 (Biomatters) sequence analysis software [13].

\section{Genotyping}

The genotypes of the isolates were established using the IS6110 restriction fragment length polymorphism (RFLP) method, as described previously [14]. 
Table 1 Primer sequences and annealing temperatures used for PCR and sequencing

\begin{tabular}{|c|c|c|c|c|c|}
\hline Gene & Primer & $\begin{array}{l}\text { Nucleotide Sequence } \\
\left(5^{\prime} \rightarrow 3^{\prime}\right)\end{array}$ & Annealing Temp $\left({ }^{\circ} \mathrm{C}\right)$ & Associated Drug Resistance & Ref \\
\hline \multirow[t]{2}{*}{$r p o B$} & $r p o B F$ & TGTTGGACATCTACCGCAAG & $54^{\circ} \mathrm{C}$ & Rifampicin & * \\
\hline & $r p o B \mathrm{R}$ & CGAGACGTCCATGTAGTCCA & & & \\
\hline \multirow[t]{2}{*}{$\operatorname{inh} A$} & $\operatorname{inh} A \mathrm{~F}$ & CTACATCGACACCGATATGAC & $55^{\circ} \mathrm{C}$ & Isoniazid & [26] \\
\hline & $\operatorname{inh} A \mathrm{R}$ & GACCGTCATCCAGTTGTAG & & & \\
\hline \multirow[t]{2}{*}{ katG } & katG F & GGTCGACATTCGCGAGACGTT & $57^{\circ} \mathrm{C}$ & Isoniazid & [27] \\
\hline & katG R & TTGTTCCTGCGACGCATCGTG & & & \\
\hline \multirow[t]{2}{*}{ pncA } & pncA F & GCTGGTCATGTTCGCGATCG & $59^{\circ} \mathrm{C}$ & Pyrazinamide & [28] \\
\hline & $p \cap c A R$ & GCTITGCGGCGAGCGCTCCA & & & \\
\hline \multirow[t]{2}{*}{$e m b B$} & $e m b B F$ & AAGCTGGCGCACCTTCAC & $55^{\circ} \mathrm{C}$ & Ethambutol & * \\
\hline & $e m b B R$ & ATAGCGCGGTGATCAAAAA & & & \\
\hline
\end{tabular}

* newly designed primers

\section{Results}

\section{RFLP analysis}

RFLP analysis revealed that most of the DS isolates belonged to the Beijing family of strains. Three DS isolates had a unique profile and 1 isolate was a variant of the F11 strain family. The F28 strain family was the predominant genotype of the MDR isolates, whereas the remaining isolates belonged to the F15/LAM4/KZN (KZN) strain family. One MDR isolate recorded a unique profile and 1 was a variant of the F28 strain family. All of the XDR isolates analysed in the study belonged to the KZN strain family. Genotypes, mutations and associated phenotypes are shown in Tables 2, 3 and 4 .

\section{rpoB mutations and RIF resistance}

Majority (73\%) of the RIF resistant isolates had at least 1 mutation in the $r p o B$ gene, while 5 RIF resistant (3 MDR, 2 XDR) isolates had no alteration within the $r p o B$

Table 2 Mutations in the rpoB, katG, pncA and embB genes with the associated MICs and genotypes of the drug susceptible isolates

\begin{tabular}{|c|c|c|c|c|c|c|c|c|}
\hline \multirow[t]{2}{*}{ Isolate } & \multirow[t]{2}{*}{ Genotype } & \multicolumn{3}{|c|}{$\mathrm{MIC}(\mathrm{mg} / \mathrm{L})$} & \multicolumn{4}{|c|}{ Mutation Profile } \\
\hline & & $\mathrm{RIF}$ & $\mathrm{INH}$ & $E M B$ & $r p o B$ & katG & pncA & $e m b B$ \\
\hline TF1538 & Unique & 1 & $\leq 0.125$ & 2 & - & - & - & - \\
\hline TF1413 & Beijing & 1 & 16 & 2 & - & G1388T & - & - \\
\hline TF1582 & Beijing & 1 & $\leq 0.125$ & 2 & - & G1388T & - & - \\
\hline TF832 & F11V & 1 & $\leq 0.125$ & 2 & - & - & - & - \\
\hline TF1519 & Beijing & 1 & $\leq 0.125$ & 2 & - & - & - & - \\
\hline TF1001 & Unique & 1 & $\leq 0.125$ & 2 & - & - & - & - \\
\hline TF933 & Unique & 1 & $\leq 0.125$ & 2 & - & - & - & - \\
\hline P090811 & Beijing & 1 & $\leq 0.125$ & 2 & - & G1388T & - & - \\
\hline P090802 & Beijing & 1 & $\leq 0.125$ & 2 & - & G1388T & - & - \\
\hline P090804 & Beijing & 1 & $\leq 0.125$ & 2 & - & G1388T & - & - \\
\hline
\end{tabular}

gene. The rроB mutations were of various types: (1) $\mathrm{A} \rightarrow \mathrm{G}$ substitution in codon 435 (A1304G, D435G); detected in 5 XDR isolates with an MIC range of 64$128 \mathrm{mg} / \mathrm{L}$, belonging to the KZN family of strains (2). $\mathrm{T} \rightarrow \mathrm{C}$ substitution in codon 452 (T1355C, L452P); detected in $1 \mathrm{MDR}$ isolate of the KZN family strain family with an MIC of $8 \mathrm{mg} / \mathrm{L}$ (3). C $\rightarrow$ T substitution in codon 450 (C1349T, S450L); detected in 6 MDR isolates which belonged to the KZN and F28 strain families with an MIC range of $32-128 \mathrm{mg} / \mathrm{L}$. Double mutants included (4) $\mathrm{C} \rightarrow \mathrm{T}$ substitution in codon 435 (C1303T, D435Y) together with an $\mathrm{C} \rightarrow \mathrm{A}$ substitution in codon 454 (C1360A, P454T); detected in 1 MDR isolate of the KZN strain family with an MIC of $128 \mathrm{mg} / \mathrm{L}(5) . \mathrm{A} \rightarrow \mathrm{T}$ substitution in codon 445 (A1334T, H445L) and a G $\rightarrow$ C substitution in codon 491 (G1473C, I491M); detected in 1 MDR isolate, a variant of the F28 strain family with an MIC of $128 \mathrm{mg} / \mathrm{L}$ (6). The S450L and L452P detected in $2 \mathrm{MDR}$ isolates of the KZN and F28 strain families with an MIC of $64 \mathrm{mg} / \mathrm{L}$; (7) the D435G and L452P detected in $21 \mathrm{XDR}$ isolates belonging to the KZN strain family with an MIC range of $32-128 \mathrm{mg} / \mathrm{L}$ (8). The S450L and a $\mathrm{T} \rightarrow \mathrm{C}$ substitution in codon 564 (T1690C, $\mathrm{Y} 564 \mathrm{H}$ ), detected in $2 \mathrm{MDR}$ isolates of the KZN strain family with an MIC of $128 \mathrm{mg} / \mathrm{L}$. No mutations were detected in any of the DS isolates screened.

\section{inhA; katG mutations and INH resistance}

No mutations were detected in the inhA gene or its promoter region amongst the isolates screened in the study. The kat $G$ mutations were of 3 types (1). G $\rightarrow$ T substitution in codon 473 (G1388T; no amino acid alteration); detected in 5 DS isolates, all belonging to the Beijing family of strains (2). $\mathrm{G} \rightarrow \mathrm{C}$ substitution in codon 315 (G944C, S315T); detected in all of the MDR and XDR isolates studied. The MIC range of the isolates was $4-16 \mathrm{mg} / \mathrm{L}$. The mutation was detected across all genotypes detected in the study (3). 
Table 3 Mutations in the rpoB, katG, pncA and embB genes with the associated MICs and genotypes of the MDR isolates

\begin{tabular}{|c|c|c|c|c|c|c|c|c|}
\hline \multirow[t]{2}{*}{ Isolate } & \multirow[t]{2}{*}{ Genotype } & \multicolumn{3}{|c|}{ MIC (mg/L) } & \multicolumn{4}{|c|}{$\begin{array}{l}\text { Mutation Profile } \\
{ }^{a} \text { Associated amino acid substitutions }\end{array}$} \\
\hline & & RIF & $\mathrm{INH}$ & $\mathrm{EMB}$ & $r p o B$ & katG & pncA & $e m b B$ \\
\hline MODS11 & $\mathrm{KZN}$ & 8 & 8 & 8 & $\mathrm{~T} 1355 \mathrm{C}$ & G944C & $\Delta \mathrm{C}$ & A916G \\
\hline MODS688 & KZN & 128 & 8 & 8 & $\begin{array}{l}\text { C1349T } \\
\text { T1690C }\end{array}$ & G944C & T416G & A916G \\
\hline TF44949 & $F 28$ & 32 & 16 & 8 & C1349T & G944C & - & A916G \\
\hline TF3251 & KZN & 128 & 16 & 16 & $\begin{array}{l}\text { G1303T } \\
\text { C1360A }\end{array}$ & G944C & - & A916G \\
\hline TF78838 & $F 28$ & 128 & 16 & 8 & C1349T & G944C & T100G & A916G \\
\hline TF2063 & $F 28$ & 128 & 16 & 16 & С1349T & G944C & $\mathrm{T} 100 \mathrm{G}$ & A916G \\
\hline TF3203 & F28 & 128 & 16 & 16 & С1349T & G944C & T100G & A916G \\
\hline TF1951 & F28V & 128 & 16 & 16 & $\begin{array}{l}\text { A1334T } \\
\text { G1473C }\end{array}$ & G944C & - & A916G \\
\hline TF64747 & $\mathrm{KZN}$ & 128 & 16 & 8 & $\begin{array}{l}\text { C1349T } \\
\text { T1690C }\end{array}$ & G944C & T416G & A916G \\
\hline TF2889 & F28 & 64 & 16 & 8 & $\begin{array}{l}\text { C1349T } \\
\text { T1355C }\end{array}$ & G944C & - & C1489A \\
\hline TF2040 & F28 & 128 & 16 & 16 & C1349T & G944C & T100G & C1489A \\
\hline MODS682 & F28 & 128 & 16 & 16 & - & G944C & - & - \\
\hline TF36480 & KZN & 128 & 16 & 8 & - & G944C & T100G & - \\
\hline TF2034 & Unique & 64 & 16 & 16 & $\begin{array}{l}\text { C1349T } \\
\text { T1355C }\end{array}$ & $\begin{array}{l}\text { G944C } \\
\text { A1343C }\end{array}$ & - & - \\
\hline TF2153 & F28 & 128 & 16 & 16 & - & G944C & $\mathrm{T} 100 \mathrm{G}$ & - \\
\hline
\end{tabular}

${ }^{a}$ rpoB: $\mathrm{C} 1303 \mathrm{~T}=\mathrm{D} 435 \mathrm{Y} ; \mathrm{A} 1334 \mathrm{~T}=\mathrm{H} 445 \mathrm{~L} ; \mathrm{C} 1349 \mathrm{~T}=\mathrm{S} 450 \mathrm{~L} ; \mathrm{T} 1355 \mathrm{C}=\mathrm{L} 452 \mathrm{P} ; \mathrm{C} 1360 \mathrm{~A}=\mathrm{P} 454 \mathrm{~T} ; \mathrm{G} 1473 \mathrm{C}=\mathrm{I491M} ; \mathrm{T} 1690 \mathrm{C}=\mathrm{Y} 564 \mathrm{H}$ katG: $\mathrm{G} 944 \mathrm{C}=\mathrm{S} 315 \mathrm{~T}$

pncA: $\Delta C=$ Insertion of cytosine at position 457; T100G = Y34D; T416G = L139G embB: $\mathrm{A} 916 \mathrm{G}=\mathrm{M} 306 \mathrm{~V} ; \mathrm{C} 1489 \mathrm{~A}=\mathrm{Q} 506 \mathrm{~K}$

One MDR isolate, unique in its genotype had double mutations within the katG gene. In addition to the S315T mutation, an $\mathrm{A} \rightarrow \mathrm{C}$ substitution in codon 468 (A1343C, N468A) was detected, associated with MIC of $16 \mathrm{mg} / \mathrm{L}$.

The remaining DS isolates had no alteration in the katG gene.

\section{pncA mutations and PZA resistance}

$p n c A$ gene mutations were of 3 types (1). $\mathrm{T} \rightarrow \mathrm{G}$ substitution in codon 34 (T100G, Y34D); detected in 6 MDR isolates, 5 of which belonged to the F28 family and the remaining isolate belonged to the $\mathrm{KZN}$ family of strains (2). $\mathrm{T} \rightarrow \mathrm{G}$ substitution in codon 139 (T416G, L139G); detected in 2 MDR isolates, belonging to the KZN family of strains (3). Insertion of a cytosine at position 457, present in $1 \mathrm{MDR}$ and all the XDR isolates screened, all belonging to the KZN strain family, resulting in a frameshift. The remaining MDR isolates and DS isolates had no alteration in the $p n c A$ gene.

\section{embB mutations and EMB resistance}

The $e m b B$ mutations were of 2 types (1). A $\rightarrow$ G substitution in codon 306 (A916G, M306V); detected in 9 MDR and all the XDR isolates, associated with an MIC range of $2-16 \mathrm{mg} / \mathrm{L}$. The mutation was detected across all genotypes of the study (2). $\mathrm{C} \rightarrow \mathrm{A}$ substitution in codon 506 (C1489A, Q506K); detected in 2 MDR isolates, belonging to the F28 family of strains and associated with an MIC of $16 \mathrm{mg} / \mathrm{L}$. The remaining MDR and DS isolates had no alteration in the $e m B$ gene.

Mutations of the $r p o B, \operatorname{inh} A, k a t G, e m b B$ and $p n c A$ genes, MIC's and associated genotypes are shown in Tables 2,3 and 4 .

\section{Discussion}

In this study, we report on the mechanisms mediating first-line drug resistance amongst clinical isolates from KwaZulu-Natal, South Africa. South Africa ranks amongst the top ten high burden countries of drug resistant tuberculosis worldwide. The overall incidence rate in the KwaZulu-Natal province alone currently exceeds the incidence rates for all types of TB in some low incidence countries, like the USA [15]. In an attempt to understand the molecular basis of first-line drug resistance in our setting, we sequenced the $\operatorname{rop} B$, inh $A$, katG, $p n c A$ and $e m b B$ genes associated with resistance to key drugs used in the treatment of DS tuberculosis. 
Table 4 Mutations in the rpoB, katG, pncA and embB genes with the associated MICs and genotypes of the XDR isolates

\begin{tabular}{|c|c|c|c|c|c|c|c|c|c|}
\hline \multirow[t]{2}{*}{ Isolate } & \multirow[t]{2}{*}{ Genotype } & \multicolumn{3}{|c|}{ MIC (mg/L) } & \multicolumn{5}{|c|}{$\begin{array}{l}\text { Mutation Profile } \\
{ }^{a} \text { Associated amino acid substitutions }\end{array}$} \\
\hline & & $\mathrm{RIF}$ & $\mathrm{INH}$ & $E M B$ & $r p o B$ & & katG & pncA & $e m b B$ \\
\hline TF1762 & KZN & 16 & 8 & 16 & A1304G & T1355C & G944C & $\Delta C$ & A916G \\
\hline MODS141 & KZN & 128 & 8 & 16 & A1304G & T1355C & G944C & $\Delta C$ & A916G \\
\hline MODS39 & KZN & 32 & 4 & 2 & A1304G & T1355C & G944C & $\Delta C$ & A916G \\
\hline MODS387 & KZN & 128 & 16 & 8 & A1304G & T1355C & G944C & $\Delta C$ & A916G \\
\hline MODS338 & $\mathrm{KZN}$ & 128 & 16 & 16 & A1304G & T1355C & G944C & $\Delta C$ & A916G \\
\hline MODS667 & KZN & 128 & 16 & 16 & A1304G & T1355C & G944C & $\Delta C$ & A916G \\
\hline MODS513 & $\mathrm{KZN}$ & 128 & 8 & 16 & A1304G & T1355C & G944C & $\Delta C$ & A916G \\
\hline MODS143 & KZN & 128 & 16 & 16 & A1304G & T1355C & G944C & $\Delta C$ & A916G \\
\hline TF1824 & KZN & 128 & 16 & 16 & A1304G & T1355C & G944C & $\Delta C$ & A916G \\
\hline TF1925 & KZN & 128 & 16 & 16 & A1304G & T1355C & G944C & $\Delta C$ & A916G \\
\hline TF66937 & KZN & 128 & 16 & 8 & A1304G & T1355C & G944C & $\Delta C$ & A916G \\
\hline TF80198 & $\mathrm{KZN}$ & 128 & 16 & 8 & A1304G & T1355C & G944C & $\Delta C$ & A916G \\
\hline TF80164 & KZN & 128 & 16 & 16 & A1304G & T1355C & G944C & $\Delta C$ & A916G \\
\hline TF1497 & $\mathrm{KZN}$ & 128 & 16 & 16 & A1304G & T1355C & G944C & $\Delta C$ & A916G \\
\hline TF75549 & KZN & 128 & 16 & 16 & A1304G & T1355C & G944C & $\Delta C$ & A916G \\
\hline TF31066 & $\mathrm{KZN}$ & 128 & 16 & 16 & A1304G & T1355C & G944C & $\Delta C$ & A916G \\
\hline TF739 & KZN & 128 & 16 & 16 & A1304G & T1355C & G944C & $\Delta C$ & A916G \\
\hline MODS370 & KZN & 128 & 16 & 16 & A1304G & T1355C & G944C & $\Delta C$ & A916G \\
\hline TF3181 & KZN & 128 & 16 & 16 & A1304G & T1355C & G944C & $\Delta C$ & A916G \\
\hline TF37806 & KZN & 128 & 16 & 16 & A1304G & T1355C & G944C & $\Delta C$ & A916G \\
\hline TF2981 & KZN & 128 & 16 & 16 & A1304G & T1355C & G944C & $\Delta C$ & A916G \\
\hline MODS334 & $\mathrm{KZN}$ & 128 & 16 & 16 & - & - & G944C & $\Delta C$ & A916G \\
\hline TF2038 & KZN & 128 & 16 & 16 & A1304G & - & G944C & $\Delta C$ & A916G \\
\hline TF3228 & $\mathrm{KZN}$ & 128 & 16 & 16 & - & - & G944C & $\Delta C$ & A916G \\
\hline TF25027 & KZN & 128 & 16 & 8 & A1304G & - & G944C & $\Delta C$ & A916G \\
\hline TF51648 & $\mathrm{KZN}$ & 128 & 16 & 16 & A1304G & - & G944C & $\Delta C$ & A916G \\
\hline TF49127 & $\mathrm{KZN}$ & 64 & 16 & 16 & A1304G & - & G944C & $\Delta C$ & A916G \\
\hline MODS 195 & KZN & 32 & 16 & 8 & A1304G & - & G944C & $\Delta C$ & A916G \\
\hline
\end{tabular}

arpoB:A1304G = D435G; T1355C $=$ L452P

katG: $\mathrm{G} 944 \mathrm{C}=\mathrm{S} 315 \mathrm{~T}$

pnc $A: \triangle C=$ Insertion of cytosine at position 457

embB: $\mathrm{A} 916 \mathrm{G}=\mathrm{M} 306 \mathrm{~V} ; \mathrm{C} 1489 \mathrm{~A}=\mathrm{Q} 506 \mathrm{~K}$

Analysis of the inhA, katG and $e m b B$ genes demonstrated classical mechanisms that have been associated with resistance to INH and EMB [5, 6]. No mutations were detected in the inhA gene or its promoter region in the isolates screened. This is in keeping with previous reports [16]. Common inhA mutations that have been reported occur in the inhA promoter region at position -15 , its correlation, however, is strongest with INH mono-resistant isolates or isolates with low-level INH resistance $[5,6]$. A recent study demonstrated that double mutations in the inh $A$ gene, in the promoter and coding regions, resulted in high-level INH resistance [17]. A large number of RIF resistant isolates bear mutations in the inhA and its promoter region making these mutations high predictors of RIF resistance, despite being absent in a subset of INH resistant isolates.

The main mechanism mediating INH resistance in the isolates studied is the katG S315T mutation that was detected in all the MDR and XDR isolates. Numerous reports have found this mutation to be the most common mutation associated with INH resistance. One MDR isolate with unique genotype had double mutations in the inhA gene:the S315T mutation occurred in conjunction with the N468A mutation. The double mutant did not record a higher MIC as compared to the other isolates bearing the S315T mutation only. The N468A appears 
to be novel, but may represent a natural polymorphism or phylogenetic marker of the unique genotype of the isolate. The G1388T mutation detected in the 5 DS isolates is natural polymorphism associated with the Beijing genotype that has no bearing on resistance.

Approximately $96 \%$ of RIF resistance is attributed to mutations contained in an 81 bp hot-spot region known as the RIF resistance determining region (RRDR) which encompasses codons 507-533 of the rpoB gene [5, 6]. Mechanisms of resistance for the MDR and XDR isolates varied in the case of RIF resistance, despite the MICs falling within a similar range. Various mutation types were described amongst the MDR isolates. The S450L (corresponding to codon 531 in E.coli) mutation was the most common, accounting for resistance in 7 MDR isolates, in keeping with various reports. Four MDR Isolates had the S450L mutation together with L452P (corresponding to codon 533 in E.coli) or the T564H mutation [16]. One MDR isolate had the L452P mutation only. One isolate had the H445L (corresponding to codon 526 in E.coli) and the I491M mutation [16]. To the best of our knowledge, the I491M and $\mathrm{T} 564 \mathrm{H}$ mutations are novel and appear to be involved in mediating RIF resistance.

The main mutation mediating RIF resistance in the XDR isolates was the D435G mutation together with the L452P mutation. This was detected in all the XDR isolates and 1 MDR isolate. Three isolates had the D435G mutation only and one isolate had the S450L mutation. Although the mutations and genotypes of the isolates were diverse, all mutations correlated with high level RIF resistance. Interestingly, the MDR and XDR isolates both had mutations in codon 435 but each resulted in different amino acid substitutions. Similar findings were described for KZN MDR and XDR isolates in a study by Ioger et al. [16] analysing the whole genome sequences of drug resistant isolates KZN strain family. The main mechanism mediating resistance in the KZN MDR isolate was attributed to the $\mathrm{D} 435 \mathrm{Y}$ mutation and the D435G and L452P mutations in the KZN XDR isolates. The study only analysed the KZN strain family [16]. Our study shows a greater diversity in the MDR RIF resistance mechanisms and the isolates represented various strain families. In our study, the mutation in codon 435 was responsible for resistance in most of the MDR isolates. In contrast, Ioger et al. reported that this mutation was only responsible for $9 \%$ of RIF resistance [16].

Resistance to PZA, as in the case of RIF was represented by diverse mutations in the MDR and XDR isolates. The MDR isolates had a mutation either in codon 34 (nucleotide 100) or codon 139 nucleotide 416), while XDR isolates had an insertion of a cytosine at position 457, leading to a frameshift in the amino acid translation. The insertion was also detected in one MDR isolate, possibly with a higher level of resistance to PZA. Due to technical difficulty associated with PZA susceptibility testing, no MICs were carried out for the drug. Instead, we sought to identify mutations in the MDR and XDR groups and compare them with published literature. Mutations at position 100 have been described in isolates in Japan and Peru while mutations at position 416 have been reported South Africa, Thailand, China, USA, Portugal, Spain and Singapore [18-26]. The insertion at position 457 has been described in isolates from Brazil [27].

Mutations within the $p n c A$ gene are highly diverse, with 600 unique mutations at 400 different positions reported to date [28]. In keeping with this diversity, the study by Ioger et al. showed different mechanisms of PZA resistance in the MDR and XDR isolates from the KZN strain family as compared to the mechanisms described in this report [14]. This highlights the difficulty associated with detection of PZA resistance. The diversity of the mutations detected in the isolates varies greatly, making it impossible to apply to molecular diagnostic assay. PZA susceptibility testing poses a further challenge. The PZase enzyme required for the conversion of PZA to its active form is only functional at an acid $\mathrm{pH}$, making it difficult to test the drug using conventional media. With a prevalence of approximately $60.5 \%$ in patients with confirmed MDR TB, PZA resistance testing is of utmost importance as PZA forms an integral role in current multidrug regimens and is also a key component of new treatment regimens undergoing evaluation in phase II or III clinical trials [29, 30].

A few isolates resistant to RIF and PZA did not display any mutations in the related genes. This phenomena has been previously described $[5,6]$. This suggests that alternate resistance mechanisms may exist that remain to be identified. The differences in resistance mechanisms in the MDR and XDR isolates suggest that the strains emerged separately and acquired resistance mutations independently. This is against the premise that the XDR phenotype had evolved directly from the MDR phenotype, consistent with previous reports [14].

\section{Conclusion}

In conclusion, we demonstrate that the M.tuberculosis strains circulating in our setting display a combination of previously observed mutations, each mediating resistance to a different drug. The MDR and XDR TB isolates analysed in this study displayed classical mutations linked to INH and EMB resistance, whilst diverse mutations were linked to RIF and PZA resistance. The observation that all XDR-TB isolates appear identical (KZN strain) is consistent with reports endemic transmission of XDR-TB in our region. This strain is highly virulent and has displayed increased fitness despite the 
burden of carrying resistance conferring mutations [31]. The results of the study underscores the need for rapid drug susceptibility testing to improve treatment efficacy and subsequent treatment outcomes. Future studies are required to determine that factors that drive the dynamic evolution of M.tuberculosis drug resistance under antibiotic pressure in patients over time. Whilst various new developments offer a ray of hope, these are years away from integration into TB programmes. Thus strengthening of public health systems and the stringent antibiotic stewardship remain critical in TB control efforts.

\begin{abstract}
Abbreviations
AMIK: Amikacin; DS: Drug susceptible; EMB: Ethambuthol; HIV: Human immunodeficiency virus; INH: Isoniazid; KAN: Kanamycin; MDR: Multidrug resistant; OADC: Oleic acid albumin dextrose catalase; PZA: Pyrazinamide; RFLP: Restriction fragment length polymorphism analysis; RIF: Rifampicin; TB: Tuberculosis; WHO: World Health Organization; XDR: Extensively drug resistant
\end{abstract}

\section{Funding}

This study was supported by the National Research Foundation (Grant number: 79484)

\section{Availability of data and materials}

Nucleotide sequences will be shared upon request.

\section{Authors' contributions}

ND was involved in the conception and design of the study, conducted the molecular assays, sequence alignment and drafted the manuscript. PM and AWS were involved in the conception and design of the study, participated in the co-ordination of the study and reviewed the manuscript for publication. All authors have read and approved the final manuscript.

\section{Competing interests}

The authors declare that they have no competing interests.

\section{Consent for publication}

Not applicable.

\section{Ethics approval and consent to participate}

Ethical approval for the study was obtained from Biomedical Research Ethics Committee of the University of KwaZulu-Natal (BREC 274/09).

Received: 14 October 2015 Accepted: 4 October 2016

Published online: 26 October 2016

\section{References}

1. World Health Organization. Global tuberculosis report. Geneva: World Health Organization; 2014. [http://apps.who.int/iris/bitstream/10665/191102/1/ 9789241565059_eng.pdf]. Accessed 25 Oct 2016.

2. National Department of Health South Africa. National Tuberculosis Treatment Guidelines. 2014. [http://www.nicd.ac.za/assets/files/ Acrobat\%20Document2.pdf]. Accessed 25 Oct 2016.

3. Fonseca JD, Knight GM, McHugh TD. The complex evolution of antibiotic resistance in Mycobacterium tuberculosis. Int J Infect Dis. 2015;32:94-100.

4. Ismail $\mathrm{N}$, Koornof $\mathrm{H}$. Tuberculosis continues to be a public health problem in South Africa from diagnosis to treatment. South African J Epidemiol Infect. 2013;28:191.

5. Da Silva PEA, Palomino JC. Molecular basis and mechanisms of drug resistance in Mycobacterium tuberculosis: Classical and new drugs. J Antimicrob Chemother. 2011;66:1417-30.

6. Palomino JC, Martin A. Drug Resistance Mechanisms in Mycobacterium tuberculosis. Antibiotics. 2014;3:317-40.

7. Zhang Y, Yew W-W. Mechanisms of drug resistance in Mycobacterium tuberculosis: update 2015. Int J Tuberc Lung Dis. 2015;19(11):1276-89.
8. Cohen KA, Abeel T, Manson McGuire A, Desjardins CA, Munsamy V, Shea TP, et al.: Evolution of Extensively Drug-Resistant Tuberculosis over Four Decades: Whole Genome Sequencing and Dating Analysis of Mycobacterium tuberculosis Isolates from KwaZulu-Natal. PLoS Med, 12(9):e1001880. doi:10.1371/journal.pmed.1001880.

9. Isenberg H. Clinical Microbiology Procedures Handbook: Susceptibility tests by modified agar Proportion. 2004.

10. World Health Organization. Guidelines for surveillance of drug resistance in tuberculosis. Geneva: World Health Organization; 2009. [http://apps.who.int/iris/ bitstream/10665/44206/1/9789241598675 eng.pdfl. Accessed 25 Oct 2016.

11. Van Soolingen D, Hermans PWM, De Haas PEW, Soll DR, Van Embden JDA. Occurrence and stability of insertion sequences in Mycobacterium tuberculosis complex strains: Evaluation of an insertion sequencedependent DNA polymorphism as a tool in the epidemiology of tuberculosis. J Clin Microbiol. 1991;29:2578-86.

12. Rozen, S and Skaletsky H. Primer 3 Software V4.0. 2009. [http://bioinfo.ut.ee/ primer3-0.4.0/primer3/]. Accessed 25 Oct 2016.

13. Drummond AJ, Ashton B. Geneious Software version 5.5.7. 2011. [http:// www.geneious.com/download]. Accessed 25 Oct 2016.

14. Van Embden JDA, Cave MD, Crawford JT, Dale JW, Eisenach KD, Gicquel B, Hermans P, Martin C, McAdam R, Shinnick TM, Small PM. Strain identification of Mycobacterium tuberculosis by DNA fingerprinting: Recommendations for a standardized methodology. J Clin Microbiol. 1993;31:406-9

15. Lim JR, Gandhi NR, Mthiyane T, Mlisana K, Moodley J, Jaglal L, Ramdin N, Brust JCM, Ismail N, Rustomjee R, Shah NS. Incidence and Geographic Distribution of Extensively Drug-Resistant Tuberculosis in KwaZulu-Natal, South Africa. PLoS One. 2015;10(7):e0132076.

16. loerger TR, Koo S, No EG, Chen X, Larsen MH, Jacobs WR, Pillay M, Sturm AW, Sacchettini JC. Genome analysis of multi- and extensively-drug-resistant tuberculosis from KwaZulu-Natal, South Africa. PLoS One. 2009;4:2-11.

17. Machado D, Couto I, Perdigão J, Rodrigues L, Portugal I, Baptista P, Veigas B, Amaral L, Viveiros M. Contribution of efflux to the emergence of isoniazid and multidrug resistance in Mycobacterium tuberculosis. PLoS One. 2012;7:e34538

18. Zhang Y, Shi W, Zhang W, Mitchison D. Mechanisms of Pyrazinamide Action and Resistance. Microbiol Spectrum. 2014;2:1-12.

19. Zimhony O, Vilche C, Jacobs WR. Characterization of Mycobacterium smegmatis Expressing the Mycobacterium tuberculosis Fatty Acid Synthase I (fas1) Gene. J Bacteriol. 2004:186:4051-5.

20. Joosten SA, Fletcher HA, Ottenhoff THM. A Helicopter Perspective on TB Biomarkers: Pathway and process based analysis of gene expression data provides new insight into TB Pathogenesis. PLoS One. 2013;8(9):e73230.

21. Diacon AH, Donald PR, Pym A, Grobusch M, Patientia RF, Mahanyele R, Bantubani N, Narasimooloo R, De Marez T. Randomized Pilot Trial of Eight Weeks of Bedaquiline (TMC207) Treatment for Multidrug-Resistant Tuberculosis : Long-Term Outcome, Tolerability, and Effect on Emergence of Drug Resistance. Antimicrob Agents Chemother. 2012;56:3271-6.

22. Kelly PM, Lumb R, Pinto A, Costa G, Sarmento J, Bastian I. Analysis of Mycobacterium tuberculosis isolates from treatment failure patients living in East Timor. Int J Tuberc Lung Dis. 2005;9:81-6.

23. Kelly PM, Ardian M, Waramori G, Anstey NM, Syahrial H, Tjitra E, Bastian I, Maguire GP, Lumb R. A community-based TB drug susceptibility study in Mimika District, Papua Province, Indonesia. 2006. Int J Tuberc Lung Dis. 2005;10:167-71.

24. Mphahlele M, Syre H, Valvatne $H$, Stavrum R, Mannsåker T, Muthivhi T, Weyer K, Fourie PB, Grewal HMS. Pyrazinamide Resistance among South African Multidrug-Resistant Mycobacterium tuberculosis Isolates. J Clin Microbiol. 2008;46:3459-64.

25. Perdigão J, Macedo R, Fernandes E, Brum L, Portugal I. Multidrug-resistant tuberculosis in Lisbon, Portugal: a molecular epidemiologic perspective. Microb Drug Resist. 2008;14:2008.

26. Whitfield MG, Soeters HM, Warren RM, York T. A Global Perspective on Pyrazinamide Resistance : Systematic Review and Meta- Analysis. PLoS One. 2015;10(7):e0133869.

27. Djuretic T, Herbert J, Drobniewski F, Yates M, Smith EG, Magee JG, Williams R, Flanagan P, Watt B, Rayner A, Crowe M, Chadwick MV, Middleton AM, Watson JM. Antibiotic resistant tuberculosis in the United Kingdom: 1993-1999. Thorax. 2002:57:477-82.

28. Yu MH, Sun YJ, Wong SY, Lee ASG. Contribution of dfrA and inhA mutations to the detection of isoniazid-resistant Mycobacterium tuberculosis isolates. Antimicrob Agents Chemother. 2009;53:4010-2. 
29. Marttila HJ, Soini H, Huovinen P, Viljanen MK. katG mutations in isoniazidresistant Mycobacterium tuberculosis isolates recovered from Finnish patients. Antimicrob Agents Chemother. 1996;40:2187-9.

30. Endoh T, Yagihashi A, Uehara N, Kobayashi D, Tsuji N, Nakamura M, Hayashi S, Fujii N, Watanabe N. Pyrazinamide resistance associated with pncA gene mutation in Mycobacterium tuberculosis in Japan. Epidemiol Infect. 2002;128:337-42.

31. Naidoo CC, Pillay M. Increased in vitro fitness of multi- and extensively drug-resistant F15/LAM4/KZN strains of Mycobacterium tuberculosis. Clin Microbiol Infect. 2014;20:0361-9.

Submit your next manuscript to BioMed Central and we will help you at every step:

- We accept pre-submission inquiries

- Our selector tool helps you to find the most relevant journal

- We provide round the clock customer support

- Convenient online submission

- Thorough peer review

- Inclusion in PubMed and all major indexing services

- Maximum visibility for your research

Submit your manuscript at www.biomedcentral.com/submit
Biomed Central 